УДК 378.091:373.3.017

DOI:

Лариса Ковальчук, кандидат педагогічних наук, доцент, доиент кафедри загальної педагогіки та педагогіки вищяої школи

Львівського національного університету імені Івана Франка

Олена Лущинська, аспірант, асистент кафедри початкової та дошкільної освіти

Львівського начіонального університету імені Івана Франка

\title{
МОДЕЛЬ ФОРМУВАННЯ ІНФОРМАЦЙНО-КОМУНІКАЦІЙНОЇ КУЛЬТУРИ МАЙБУТНІХ ВЧИТЕЛІВ ПОЧАТКОВИХ КЛАСІВ У ПРОЦЕСІ ПРОФЕСІЙНОӤ ПІДГОТОВКИ
}

Розкрито сутність інформаційно-комунікаційної культури вчителя початкових класів. Обтрунтовано модель формування інформачійно-комунікачійної культури як иілісну педагогічну систему поетапної професійної підготовки майбутніх учителів початкових класів, спрямованої на набуття компетентностей, необхідних для ефективної інформатизачії освітнього процесу. Цільовий, організаційно-методичний контрольно-результативний блоки моделі відображають внутрімню організацію та функціонування структурних компонентів інформаційно-комунікаційної культури, аспекти ї̈ формування.

Ключові слова: інформаційно-комунікачійна культура; модель; майбутні вчителі початкових класів; професійна підготовка.

Puc. 1. Лim. 5.

Larysa Kovalchuk, Ph.D.(Pedagogy), Associate Professor, Associate Professor of the General Pedagogics and Pedagogics of Higher School Department, Ivan Franko National University of Lviv Olena Lushchynska, Postgraduate Student, Assistant of the Primary and Preschool Education Faculty, Ivan Franko National University of Lviv

\section{THE MODEL OF FORMATION OF INFORMATION AND COMMUNICATION CULTURE OF FUTURE PRIMARY SCHOOL TEACHERS IN THE PROCESS OF PROFESSIONAL TRAINING}

The author outlines the concept of information and communication culture of primary school teachers. The model of formation of information and communication culture is described, which represents a holistic pedagogical system of step - by - step professional training of future primary school teachers, aimed at acquiring the necessary competencies for effective informatization of the educational process. The presented model reflects the internal organization and functioning of all structural components of the information and communication culture and the main aspects of its formation. The author's model includes three blocks: target, organizational-methodical and controleffective. The target block includes the purpose and objectives of professional training of future teachers. The contentmethodical block covers the components of information and communication culture (motivational-cognitive, contentactivity, analytical-evaluation, integration-operational), as well as the principles, technologies, forms, methods and means of achieving the goal. The control-effective block includes both levels (researcher, experimenter, expert, user, observer) and criteria (information-communication, communication-activity, reflective, projective-methodical) and indicators of formation of components of information-communication culture of future primary school teachers.

Selected stages of professional training of future primary school teachers ensured the formation of a high level of information and communication culture:

- theoretical (the purpose of this stage was to form knowledge, skills and abilities of organization of educational and cognitive activities of primary school students, the formation of positive belief and stable motivation);

- theoretical and practical (purpose: formation of knowledge, skills, abilities of use of separate computer technologies in the course of training and performance of tasks. Acquaintance with the maintenance and a technique of teaching of educational disciplines of elementary school);

- stage of perspective modeling (goal: formation of skills of perspective modeling, integrated use of information communication tecnologies in the educational process of primary school, information and communication culture of future teachers).

The article defines and theoretically substantiates the pedagogical conditions for the formation of information and communication culture in future primary school teachers.

Keywords: information and communication culture; model; future primary school teachers; professional training.

$\Pi$ остановка проблеми. Формування інформаційно-комунікаційної культури майбутніх учителів початкових класів у процесі професійної підготовки належить до однієї з найбільш актуальних проблем сьогодення. У період карантинних обмежень й організації 


\section{МОДЕЛЬ ФОРМУВАННЯ ІНФОРМАЦЙНО-КОМУНІКАЦІЙНОӤ КУЛЬТУРИ МАЙБУТНІХ ВЧИТЕЛІВ ПОЧАТКОВИХ КЛАСІВ У ПРОЦЕСІ ПРОФЕСІЙНОӤ ПІДГОТОВКИ}

дистанційної освіти особливо широкого поширення набули інформаційно-комунікаційні технології не тільки як засоби зв’язку, налагодження комунікації, обміну, пошуку, отримання й поширення інформації, а й технології організації освітнього процесу у закладах усіх рівнів освіти.

Аналіз останніх досліджень і публікацій засвідчує, що проблему використання інформаційнокомунікаційних технологій в освітньому процесі розглядали у своїх працях Р. Гуревич, С. Гунько, М. Жалдак, М. Кадемія, Ю. Машбиць, Н. Морзе, Л. Морська, Е. Полат, І. Роберт, Ю. Триус, С. Христочевський та ін. Окрему увагу науковці приділяють використанню Інтернет-технологій в освітньому процесі (В. Биков, Т. Винарчук, А. Вітковська-Палень, О. Глазунова, Р. Гуревич, Л. Долінер, І. Захаров, Н. Морзе, К. Обухова, В. Осадчий, Є. Патаракін, Є. Полат, Т. Пуніна, I. Роберт, А. Тихонова, Г. Стеценко та ін.). Проблема формування інформаційної культури знайшла відображення у студіях С. Алексєєвої, М. Антонченка, Т. Бабенко, О. Барановської, К. Буяльської, Г. Вишинської, Я. Галети, А. Долі, О. Ігнатової, Р. Гуревича, А. Коломієць, В. Лукашів, М. Левшина, В. Мазур, О. Шестопалюк та ін.

Мета статті полягає в теоретичному обгрунтуванні структурно-функціональної моделі формування інформаційно-комунікаційної культури майбутніх учителів початкових класів в процесі професійної підготовки.

Виклад основного матеріалу. У дослідженні виходимо з того, що інформаційно-комунікаційна культура вчителя початкових класів - це підструктура педагогічної культури, яка інтегрує у собі професійні знання, вміння й навички роботи в інформаційному середовищі, комунікативні здібності, дотримання професійної етики та естетики у використанні пропонованих і створенні власних інформаційних продуктів для здійснення освітньої діяльності. Під інформаційнокомунікаційною культурою (ІКК) розуміємо рівень використання інформаційно-комунікаційних технологій (ІКТ), який дає змогу вчителеві успішно організовувати освітній процес та створювати власний інтерактивний простір. Ми вважаємо: що вищий рівень ІКК вчителя, то вищий рівень використання IКТ, тобто рівень культури засвідчує не тільки наявність теоретичних знань, а й здатність до практичної їхньої реалізації, активного використання IКТ на різних етапах освітнього процесу.

Під моделлю (лат. modulus - міра, зразок, норма) науковці розуміють:

- засіб спілкування, який дає змогу точніше сформулювати основні поняття і стисло описати систему, пояснити причиново-наслідкові зв'язки та загальну структуру системи, що досліджується і моделюється (С. Важинський, Т. Щербак) [1, 74];

- засіб осмислення дійсності, що дає можливість упорядкувати та формалізувати початкові уявлення про об’ єкт дослідження $[1,77]$;

- аналог, замінник оригіналу (фрагмента дійсності), який за певних умов відтворює властивості оригіналу, що цікавлять дослідника (Л. Зданевич) [4, 136-154];

- результат моделювання, аналітичний або графічний опис розглянутого процесу ( Л. ДзюбаШпурик) [3, 95].

Модель є джерелом інформації про об'єкт і допомагає пояснити, зрозуміти або вдосконалити його. Беручи до уваги дослідження Д. Ланде, зазначимо, що модель $є$ провідною ланкою між дослідником і педагогічним явищем (процесами й об'єктом), виконує функції його замінника та дає змогу здобути нові знання про те, що вивчається $[5,220]$.

У довідковій літературі зазначено, що моделювання доцільно розглядати як метод дослідження об'єктів пізнання, що передбачає побудову і вивчення моделей предметів і явищ, які реально існують, а також конструйованих об'єктів з метою визначення або поліпшення їхніх характеристик [2].

При створенні моделі формування інформаційно-комунікаційної культури майбутніх учителів початкових класів ми враховували сучасний стан розвитку інформаційнокомунікаційних технологій, суспільні запити i потреби суспільства, професійну спрямованість здобувачів вищої освіти. У межах нашого дослідження обираємо форму структурнофункціональної моделі, яка відображає внутрішню організацію та функціонування всіх структурних компонентів ІКК та головні аспекти іï формування. Розроблену модель подаємо на рис. 1.

Як видно з рис. 1, авторська модель включає три блоки: цільовий, організаційно-методичний, контрольно-результативний.

Цільовий блок репрезентованої моделі включає мету, завдання, які спрямовано на досягнення результату. Мета - формування високого і достатнього рівнів інформаційнокомунікаційної культури майбутніх учителів початкових класів. Сформувати у процесі професійної підготовки в майбутніх учителів початкових класів високий і достатній рівні ІКК головним завданням, що забезпечує досягнення мети і передбачає:

- засвоєння знань про структуру і сутність IКК;

- формування знань про види IКТ і методику 


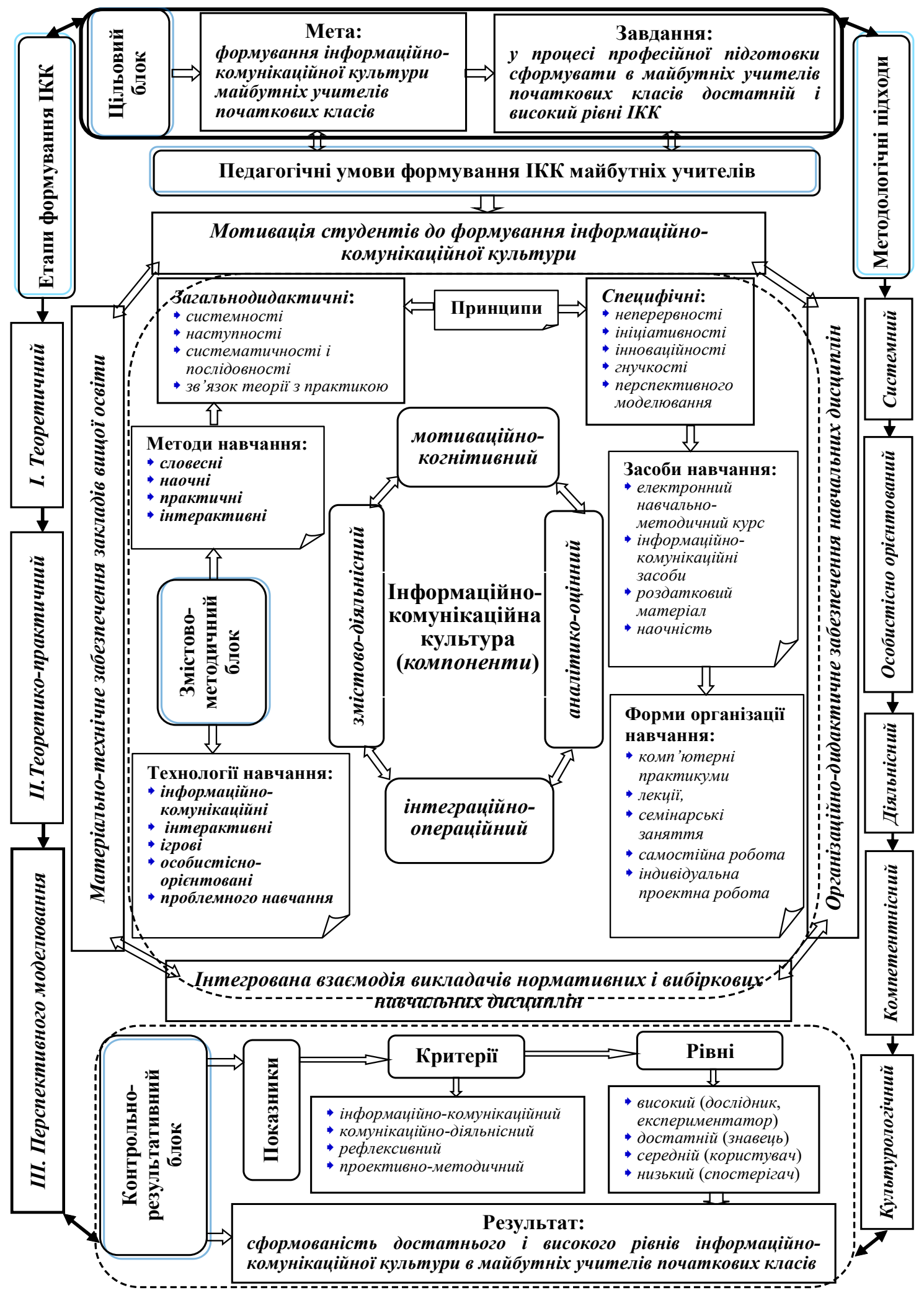

Рис. 1. Модель формування ІКК вчителя початкових класів 


\section{МОДЕЛЬ ФОРМУВАННЯ ІНФОРМАЦЙНО-КОМУНІКАЦЙННОЇ КУЛЬТУРИ МАЙБУТНІХ ВЧИТЕЛІВ ПОЧАТКОВИХ КЛАСІВ У ПРОЦЕСІ ПРОФЕСІЙНОӤ ПДГОТОВКИ}

їх використання у процесі організації навчання у початкових класах;

- формування вмінь активно використовувати IКТ на різних етапах освітнього процесу в початковій школі;

- формування перспективного моделювання використання досліджуваних технологій, бажання до саморозвитку і самовдосконалення, обміну досвідом.

Другим у нашій моделі є змістовометодичний блок, який включає етапи, принциипи, зміст, форми, методи, технологї, засоби навчання, що забезпечують реалізацію формування інформаційно-комунікаційної культури майбутніх учителів початкових класів у процесі професійної підготовки.

Як видно з рис. 1, ІКК є складною системою, структуру якої складає низка взаємопов'язаних компонентів. На основі теоретичного аналізу наукових праць зазначених вище авторів і особистого науково-практичного досвіду виокремлюємо такі компоненти інформаційнокомунікаційної культури вчителя початкових класів: мотиваційно-когнітивний, змістоводіяльнісний, аналітико-оиінний, інтеграційноопераціийний. Установлені взаємозв'язки між визначеними компонентами та структурними елементами запропонованої моделі характеризують iї як систему, що потребує певного теоретичного обгрунтування. Розглянемо детальніше виокремлені нами компоненти.

Мотиваційно-когнітивний компонент інформаційно-комунікаційної культури майбутніх учителів початкових класів полягає у взаємопов'язаності процесу отримання знань 3 внутрішньою і зовнішньою мотивацією і включає:

- високий рівень потреб у самовдосконаленні, професійному розвиткові, підвищенні власної професійності; бажання до постійного збагачення знань, розвитку професійних здібностей;

- високий рівень мотивації, спрямований на пізнання і освоєння широкого спектру технологій, методів, засобів організації освітнього процесу в початковій ланці освіти;

- комплекс психологічних, педагогічних, методичних знань щодо організації освітнього процесу в початковій школі;

- знання сучасних інформаційно-комунікаційних технологій, які використовуються в освітньому процесі початкової школи;

- використання теоретичних знань на практиці, знання особливостей і способів організації освітньої діяльності.

Змістово-діяльнісний кампонент характеризується сукупністю таких знань, умінь і навичок:

- знання змісту системи початкової освіти;
- урахування особливостей розвитку учнів задля успішної організації освітнього процесу;

- уміння визначати мету і знаходити шляхи іiі досягнення;

- уміння використовувати інформаційнокомунікаційні технології;

- володіння формами, методами, прийомами ефективної організації освітнього процесу;

- уміння раціонально і творчо інтегрувати інформаційно-комунікаційні технології у систему початкової освіти;

- високий рівень педагогічного мислення.

Аналітико-оцінний компонент передбачає формування у майбутніх учителів таких знань, умінь і навичок:

- аналізувати педагогічні ситуації;

- планувати і прогнозувати освітній процес учнів початкових класів;

- уміння аналізувати і оцінювати обрані технології, упроваджувати їх в освітній процес початкової школи;

- аналізувати педагогічну діяльність і оцінювати рівень ефективності використаного психологопедагогічного інструментарію;

- аналізувати й адекватно оцінювати власну педагогічну діяльність.

Інтеграційно-операційний компонент включає:

- поєднання знань і вмінь, інтегрування здобутих знань і вмінь задля успішної реалізації поставленої мети;

- проєктування здобутих знань, які сприятимуть формуванню вмінь перспективного моделювання у процесі створення власних інформаційнокомунікаційних продуктів, використання наявних.

Формування інформаційно-комунікаційної культури майбутніх учителів початкових класів, за нашим дослідженням, включає три етапи i знаходить реалізацію у змісті навчальних дисциплін нормативного і вибіркового циклів.

На основі аналізу навчальних і робочих планів професійної підготовки майбутніх учителів початкових класів у закладах вищої освіти виокремимо і охарактеризуємо етапи формування інформаційно-комунікаційної культури.

Першим етапом формування IKК $\epsilon$ теоретичний, який передбачає ознайомлення з інформаційно-комунікаційними технологіями, принципами роботи; ознайомлення з дидактичною і методичною системами організації освітнього процесу в початковій школі; вивчення психологічних особливостей когнітивного поведінкового розвитку здобувачів початкової освіти. Мета цього етапу полягає у формуванні знань, умінь і навичок організації навчально- 


\section{МОДЕЛЬ ФОРМУВАННЯ ІНФОРМАЦЙНО-КОМУНІКАЦІЙНОӤ КУЛЬТУРИ МАЙБУТНІХ ВЧИТЕЛІВ}

ПОЧАТКОВИХ КЛАСІВ У ПРОЦЕСІПРОФЕСІЙНОӤ ПДГОТОВКИ

пізнавальної діяльності учнів початкових класів, формування позитивного переконання та стійкої мотивації використання IКТ у професійній діяльності, вивченні загальних програм, формуванні вмінь користуватись комп’ютерними технологіями. Тривалість етапу - I курс професійної підготовки майбутніх учителів початкових класів. Під час цього етапу студенти вивчають дисципліни нормативного циклу:

- основи інформатики з методикою навчання (формування базових навичок використання комп'ютерних технологій у повсякденній діяльності, формування знань, умінь і навичок ефективного використання сучасних інформаційних технологій у процесі викладання початкового курсу інформатики як окремої навчальної дисципліни);

- психологія загальна, вікова та педагогічна (психологічними і віковими особливостями розвитку учнів початкових класів);

- вступ до спеціальності з основами педагогіки (ознайомлення 3 категоріальним і змістовим апаратами педагогіки).

Другим етапом є теоретико-практичний, який полягає у формуванні знань і вмінь використовувати IКТ. Його мета - формування знань, умінь, навичок використання окремих комп'ютерних технологій у процесі навчання і виконання завдань, ознайомлення зі змістом i методикою викладання навчальних дисциплін початкової школи. Тривалість етапу - II і III курси професійної підготовки майбутніх учителів початкових класів.

Третій етап - eman перспективного моделювання, який передбачає творення продуктів ІКТ для використання у професійній діяльності. Мета цього етапу полягає у набутті вмінь перспективного моделювання, інтегрованого використання ІКТ в освітньому процесі початкової школи, формуванні інформаційно-комунікаційної культури майбутніх вчителів. Тривалість етапу IV курс професійної підготовки майбутніх учителів початкових класів. Під час цього етапу в рамках вивчення дисципліни “Педагогічні технології в початковій школі” і проходження педагогічної практики, студенти виконують завдання, спрямовані на формування ІКК. Це завершальний етап, під час якого студенти активно впроваджують здобуті знання у власну професійну діяльність, доповнюють особистий інструментарій, створюють і наповнюють портфоліо, вчаться моделювати і творчо інтерпретувати використання кожної технології.

Контрольно-результативний блок репрезентує показники, рівні і критерії сформованості інформаційно-комунікаційної культури майбутніх учителів початкових класів, включає конкретні етапи, а саме: діагностичний (етап констатувального етапу експерименту, під час якого з'ясовано дійсний рівень сформованості інформаційно-комунікацйної культури вчителів початкових класів, проблеми і труднощі впровадження ІКТ в систему початкової школи, реальний стан сучасного освітньоінформаційного середовища і потреби учнів початкових класів); формувальний (етап дослідження, під час якого реалізовано модель й упроваджено організаційно-педагогічні умови); контрольний (етап експериментальної перевірки упровадженої моделі).

Ураховуючи підходи науковців і результати проведених нами досліджень, виокремимо чотири рівні сформованості інформаційно-комунікаційної культури майбутніх учителів початкових класів: низький, середній, достатній, високий. Охарактеризуємо кожен.

Низький (рівень спостерігача) виявляють студенти, у яких низька мотивація, переконання в неефективності використання IКТ в освітньому процесі початкової школи, використання технологій для пошуку зображень, готових відеоматеріалів, інформації, підготовки до уроку. Використовують соціальні мережі, мобільні додатки як засоби комунікації та представлення особистої інформації. Не мають бажання відкривати та опановувати нові технології.

Середній (рівень користувача) притаманний студентам, які усвідомлюють своє місце в інфосередовищі, демонструють середній рівень пошуку, відбору, систематизації, аналізу, обробки інформації, оцінки ії корисності та цілеспрямоване застосування у перспективі для розвязання поставлених навчальних завдань; виявляють невисокий рівень умінь аналізувати, планувати, оцінювати і свідомо контролювати результати своєї діяльності, рівень розвитку особистісних досягнень та дії учнів початкової школи.

Достатній (рівень знавця) властивий студентам, яких характеризує уміння використовувати прикладне програмне забезпечення (текстовий редактор, редактор презентацій, редактор публікацій) для розробки дидактичного матеріалу, використовувати соціальні сервіси для комунікації 3 батьками і колегами, використовувати вебтехнологій для розробки дидактичних матеріалів, інтерактивних вправ, контрольних і тестових робіт, відеоматеріалів, книг для читання, використання вебсайтів, порталів, сторінок із безкоштовним контентом для організації освітнього процесу, бажання використовувати IКТ в освітньому процесі початкової школи і залучати 


\section{МОДЕЛЬ ФОРМУВАННЯ ІНФОРМАЦЙНО-КОМУНІКАЦІЙНОӤ КУЛЬТУРИМАЙБУТНІХ ВЧИТЕЛІВ ПОЧАТКОВИХ КЛАСІВ У ПРОЦЕСІПРОФЕСІЙНОӤ ПІДГОТОВКИ}

учнів. Уміння подавати інформацію в різних формах (малюнки, графіки, таблиці, діаграми, відео, звук, мультимедіа тощо); володіння сучасними IКТ: прийом, переробка, передача i перетворення інформації (читання, конспектування), масмедійні, мультимедійні технології, комп'ютерна грамотність, володіння інтернет-технологіями; здатність і готовність організовувати професійнопедагогічну діяльність 3 використанням IKT, здійснювати інформаційну взаємодію між учасниками освітнього процесу.

Високий (рівень дослідника-експериментатора) передбачає вміння активно і творчо використовувати ІКТ в освітньому процесі початкової ланки освіти, а також залучати до використання учнями початкових класів; уміння обирати та опановувати нові ІКТ для використання в освітньому процесі початкової школи, вести персональну сторінку 3 метою обміну досвідом, організування проєктів із використанням ІКТ, сформованість таких важливих для вчителя якостей і властивостей як креативність, ініціативність, націленість на співпрацю, упевненість в собі, схильність до самоаналізу. Здатність студента до самопізнання і самореалізації, високий рівень готовності планувати, відбирати, синтезувати і конструювати навчальний матеріал із використанням IКТ. Знання класичних і сучасних технологій, форм, методів, засобів, прийомів навчання і виховання в початковій школі.

На основі опрацьованої літератури, а також проведеного дослідження перелічимо критерії, які характеризують компоненти інформаційнокомунікаційної культури:

- інформаційно-комунікаційний;

- комунікаційно-діяльнісний;

- проєктивно-методичний;

- рефлексивний.

На основі науково-теоретичного аналізу науково-літературних джерел, багаторічного досвіду, проведеного дослідження, нами виокремлено такі педагогічні умови формування інформаційно-комунікаційної культури у майбутніх учителів початкових класів:

1) мотивація студентів до формування інформаційно-комунікаційної культури;

2) матеріально-технічне забезпечення закладів вищої освіти;

3) інтегрована взаємодія викладачів нормативних і вибіркових навчальних дисциплін;

4) організаційно-дидактичне забезпечення навчальних дисциплін.

Отже, розроблена і запропонована нами модель формування інформаційно-комунікаційної культури у процесі професійної підготовки забезпечить формування високого і достатнього рівнів у майбутніх вчителів початкових класів. Перспективи подальшого дослідження вбачаємо у пошуку нових методів професійної підготовки у процесі формування інформаційно-комунікаційної культури.

\section{ЛІТЕРАТУРА}

1. Важинський С. Е., Щербак Т. І. Методика та організація наукових досліджень : навч. пос. Суми : СумДПУ імені А. С. Макаренка, 2016. 260 с.

2. Варгас В. М. Використання комп'ютерних технологій у підвищенні ефективності діяльності викладачів. URL: http://intkonf.org/vargas-vmvikoristannya-kompyuternih-tehnologiy-u-pidvischenniefektivnosti-diyalnosti-vikladachiv/.

3. Дзюба-Шпурик Л. Г. Формування готовності майбутніх учителів початкової школи до ознайомлення учнів з інформаційно-комунікаційними технологіями: дис. канд. пед. наук : 13.00.04. Полтава, 2016.290 с.

4. Земелько І. С. Розвиток інформаційного суспільства. Проблема цифрової нерівності. Практична медіаосвіта: авторські уроки : збірка / упорядн.: В.Ф. Іванова, О.В. Волошенюк / за наук. редакцією В. В. Різуна та В.В. Літостанао. Київ: Академія української преси: Центр вільної преси, 2013. С. 57-58.

5. Лапінський В. В. Мультимедійна дошка. Київ: Шкільний світ, 2011. 128 с.

\section{REFERENCES}

1. Vazhynskyi, S. E. \& Shcherbak, T. I. (2016). Metodyka ta orhanizatsiia naukovykh doslidzhen. [Methods and organization of scientific research]. Tutorial. Sumy, p. 260. [in Ukrainian].

2. Varhas, V. M. Vykorystannia kompiuternykh tekhnolohii u pidvyshchenni efektyvnosti diialnosti vykladachiv. [The use of computer technology to increase the efficiency of teachers]. Available at: http://intkonf.org/ vargas-vm-vikoristannya-kompyuternih-tehnologiy-upidvischenni-efektivnosti-diyalnosti-vikladachiv (accessed 24 Nov. 2020). [in Ukrainian].

3. Dziuba-Shpuryk, L. H. (2016). Formuvannia hotovnosti maibutnikh uchyteliv pochatkovoi shkoly do oznaiomlennia uchniv z informatsiino-komunikatsiinymy tekhnolohiiamy [Formation of readiness of future primary school teachers to acquaint students with information and communication technologies]. Candidate's thesis. Poltava, 290 p. [in Ukrainian].

4. Zemelko, I. S. (2013). Rozvytok informatsiinoho suspilstva. Problema tsyfrovoi nerivnosti [Development of information society. The problem of digital inequality. Information and communication technologies]. Practical media education: the author's lessons: collection (Ed.).V.F. Ivanova, O.V. Volosheniuk. According to the scientific edition V. V. Rizuna \& V.V. Litostanao. Kyiv, pp. 57-58. [in Ukrainian].

5. Lapinskyi, V. V. (2011). Multymediina doshka [Interactive board]. Kyiv, 128 p. [in Ukrainian].

Стаття надійшла до редакції 03.11.2020 